\title{
Evolution of phospholipid contents during the production of quark cheese from buttermilk
}

\author{
T. Ferreiro, ${ }^{*}$ S. Martínez,† L. Gayoso, ${ }^{*}$ and J. L. Rodríguez-Otero*1 \\ *Instituto de Investigación e Análises Aliimentarias, Universidade de Santiago de Compostela, Facultade de Veterinaria, 27002 Lugo, Spain \\ †INNOLACT S.L. Poligono Industrial, Castro de Ribeiras de Lea, 27260 Lugo, Spain
}

\begin{abstract}
We report the evolution of phosphatidylethanolamine (PE), phosphatidylinositol (PI), phosphatidylcholine (PC), phosphatidylserine (PS), and sphingomyelin (SM) contents during the production of quark cheese from buttermilk by successive ultrafiltration concentration, enrichment with cream, concurrent homogenization and pasteurization, fermentative coagulation, and separation of quark from whey by further ultrafiltration. Buttermilk is richer than milk itself in phospholipids that afford desirable functional and technological properties, and is widely used in dairy products. To investigate how phospholipid content is affected by end-product production processes such as ultrafiltration, homogenization, pasteurization or coagulation, we measured the phospholipids at several stages of each of 5 industrial-scale quark cheese production runs. In each run, 10,000 L of buttermilk was concentrated to half volume by ultrafiltration, enriched with cream, homogenized, pasteurized, inoculated with lactic acid bacteria, incubated to coagulation, and once more concentrated to half volume by ultrafiltration. Phospholipid contents were determined by HPLC with evaporative light scattering detection in the starting buttermilk, concentrated buttermilk, ultrafiltrate, cream-enriched concentrated buttermilk (both before and after concurrent homogenization and pasteurization), coagulate, and quark, and also in the rinsings obtained when the ultrafiltration equipment was washed following initial concentration. The average phospholipid content of buttermilk was approximately 5 times that of milk, and the phospholipid content of buttermilk fat 26 to 29 times that of milk fat. Although phospholipids did not cross ultrafiltration membranes, significant losses occurred during ultrafiltration (due to retention on the membranes) and during the homogenization and pasteurization process. During coagulation, however, phos-
\end{abstract}

Received January 6, 2016

Accepted March 2, 2016.

${ }^{1}$ Corresponding author: jlr.otero@usc.es pholipid content rose, presumably as a consequence of the proliferation of the inoculated lactic acid bacteria. In spite of these changes in total phospholipid content, the relative proportions of the phospholipids studied remain fairly stable throughout quark production (PE $>\mathrm{PC}>\mathrm{SM}>\mathrm{PS}>\mathrm{PI}$ ) and similar to those found in the milk of the region, except that SM content was lower than in milk.

Key words: phospholipids, buttermilk, ultrafiltration, quark production

\section{INTRODUCTION}

Traditional buttermilk is the aqueous phase left when cream is churned to butter. It contains all the water-soluble components of cream, including not only proteins, lactose, and minerals (Sodini et al., 2006; Vanderghem et al., 2010), but also glycero- and sphingophospholipids, the main structural components of the membranes delimiting milk fat globules (and, of course, of other biological membranes). The phospholipid content of buttermilk is greater than that of milk because the fragmented membranes of milk fat globules disrupted during churning mostly migrate to the aqueous phase (Corredig et al., 2003; Vanderghem et al., 2010).

As butter is produced from cream with a fat content of around $40 \%$ (wt/wt), the world production of buttermilk may be estimated as similar to the world production of butter, which in 2013 was approximately 5.2 million tonnes (FAOSTAT, 2015). Long considered a low-value by-product, buttermilk is now widely used both as the basis of beverages and certain types of cheese, and as an ingredient of other foods that has high emulsifying capacity, adds flavor, and affords the functional and technological properties of its high phospholipid content (Kuchta et al., 1996; Vesper et al., 1999; Spitsberg, 2005; Duivenvoorden et al., 2006; Dewettinck et al., 2008; Contarini and Povolo, 2013). Several of these uses require that buttermilk be subjected to processes such as homogenization, pasteurization, and coagulation. Currently microfiltration and UF have also achieved an important development in the dairy industry, including its application to but- 
termilk (Mistry et al., 1996; Govindasamy-Lucey et al., 2007). However, phospholipid content can be altered by heat treatment (Corredig and Dalgleish, 1998; Ye et al., 2004; Morin et al., 2007), by homogenization (Lee and Sherbon, 2002; Morin et al., 2007), and by filtration (Morin et al., 2004).

In the work reported here, we investigated the evolution of phosphatidylethanolamine, phosphatidylinositol, phosphatidylcholine, phosphatidylserine, and sphingomyelin contents during successive stages of the production of quark cheese from buttermilk by UF concentration, homogenization, pasteurization, fermentative coagulation, and separation of quark from whey by further UF.

\section{MATERIALS AND METHODS}

\section{Quark Production}

Phospholipids were determined during 5 industrialscale production runs, in each of which the raw material was $10,000 \mathrm{~L}$ of buttermilk obtained in the production of butter by the NIZO method from cream with a fat content of $40 \%$ that had previously been pasteurized for $30 \mathrm{~s}$ at $90^{\circ} \mathrm{C}$. Quark cheese was produced in 5 stages, as follows.

1) The starting buttermilk was concentrated to half volume by $\mathrm{UF}$ at 45 to $50^{\circ} \mathrm{C}$ using membranes with a $50 \mathrm{kDa}$ cut-off and a maximum pressure of $800 \mathrm{kPa}$.

2) Cream with a fat content of approximately $40 \%$ was added to the concentrated buttermilk to increase its fat-to-protein ratio.

3) To reduce its microbial burden, denature proteins, and improve its texture, the creamenriched buttermilk was pasteurized for 5 min at 90 to $95^{\circ} \mathrm{C}$, with concurrent homogenization at $70^{\circ} \mathrm{C}$ and $15 \mathrm{MPa}$.

4) After cooling to around $30^{\circ} \mathrm{C}$, the pasteurized, homogenized, cream-enriched buttermilk was inoculated with Lactococcus lactis ssp. lactis, L. lactis ssp. cremoris, and L. lactis ssp. lactis var. diacetylactis and incubated to coagulation at $\mathrm{pH} 4.6$.

5) The resulting coagulate was separated into quark and permeate by UF using the same membranes and conditions as in stage 1 .

In each run, samples were taken from the starting buttermilk, concentrated buttermilk, cream-enriched concentrated buttermilk (both before and after homogenization and pasteurization), coagulate, and quark, and also from the ultrafiltrate and from the rinsings ob- tained when the UF equipment was washed with $300 \mathrm{~L}$ of water. Pending analysis, all samples were stored in a refrigerator or were frozen and stored at subzero temperatures, as appropriate.

\section{Analytical Methods}

Fat. The fat content of buttermilk was determined in accordance with FIL-IDF standard 141C:2000 (FILIDF, 2000) by infrared spectrometry in a Milkoscan FT2 apparatus (Foss Electric A/S, Hillerød, Denmark) after warming to $40^{\circ} \mathrm{C}$. Quark fat content was determined by the Van-Gulik method in accordance with FIL-IDF 222 (FIL-IDF, 2008). The fat contents of other samples were determined by the Rose-Gottlieb method in accordance with FIL-IDF 1D (FIL-IDF, 1996). All fat determinations were performed in duplicate.

Phospholipids. The phospholipid fraction was considered to consist entirely of phosphatidylethanolamine (PE), phosphatidylinositol (PI), phosphatidylcholine (PC), phosphatidylserine (PS), and sphingomyelin (SM). Phospholipids were extracted and PE, PI, PC, PS, and SM were determined using slightly modified versions of the methods of Rombaut et al. (2005). Briefly, phospholipids were extracted into chloroform:methanol in proportion $2: 1$ and the extracts were stored at $-42^{\circ} \mathrm{C}$ in amber vials pending analysis by HPLC. All samples were extracted in duplicate. The HPLC apparatus (Shimadzu, Kyoto, Japan), comprising a degasser, a solvent delivery module, a controller module, a column oven, a Rheodyne manual injector valve, and an interface module, was used with a $150 \times 3.0 \mathrm{~mm}, 3 \mu \mathrm{m}$ particle diameter Prevail silica column (Grace, Deerfield, IL) and a precolumn with the same packing. Samples were eluted with chloroform:methanol:buffer (buffer being $0.5 \%$ formic acid brought to $\mathrm{pH} 6$ with ammonium hydroxide) in proportions of 80:19.5:0.5 for $17 \mathrm{~min}$ and 60:33:7 for the next $3 \mathrm{~min}$, after which the mobile phase returned to the initial conditions until the next injection 15 min later. The mobile phase flow rate was $0.5 \mathrm{~mL} /$ min and the column oven temperature was $35^{\circ} \mathrm{C}$. The injection volume was $20 \mu \mathrm{L}$. The detector was a Shimadzu ELSD-LTII low-temperature evaporative light scattering detector operated at $50^{\circ} \mathrm{C}$, a nebulizer $\left(\mathrm{N}_{2}\right)$ pressure of $350 \mathrm{kPa}$, and a gain of 3 . The phospholipids of interest were identified by comparison of their retention times with those of pure standards. All extracts were run in duplicate.

\section{Statistical Analysis}

Fat and phospholipid contents are presented as means \pm standard deviations of the 5 runs. Total phospholipid was defined as the sum of the 5 phospholipids consid- 
Table 1. Means \pm standard deviations (of 5 runs) of the fat contents (\% wt/wt) and phospholipid contents (mg/100 g) of the raw material and intermediate and final products in the production of buttermilk quark, and of the rinsings from washing UF equipment

\begin{tabular}{|c|c|c|c|c|c|c|c|}
\hline Product & Fat & $\begin{array}{c}\text { Total } \\
\text { phospholipid }\end{array}$ & $\mathrm{PE}$ & PI & $\mathrm{PC}$ & PS & SM \\
\hline Buttermilk & $0.73 \pm 0.05$ & $154.0 \pm 34.8$ & $60.9 \pm 9.7$ & $11.1 \pm 3.2$ & $39.6 \pm 9.7$ & $16.7 \pm 11.2$ & $25.7 \pm 5.2$ \\
\hline $\begin{array}{l}\text { Pasteurized cream-enriched } \\
\text { concentrated buttermilk }\end{array}$ & $4.89 \pm 1.12$ & $211.3 \pm 29.8$ & $78.2 \pm 15.8$ & $17.2 \pm 3.1$ & $57.5 \pm 4.4$ & $22.6 \pm 12.8$ & $35.8 \pm 5.5$ \\
\hline Rinsings & $3.89 \pm 0.62$ & $170.6 \pm 66.7$ & $62.8 \pm 23.0$ & $11.2 \pm 3.7$ & $45.3 \pm 16.0$ & $19.1 \pm 15.3$ & $32.1 \pm 12.2$ \\
\hline
\end{tabular}

ered. Comparisons between the phospholipid contents of different types of sample were performed by means of one-tailed Student's $t$-tests for paired samples.

\section{RESULTS AND DISCUSSION}

For each type of sample except ultrafiltrate, Table 1 lists fat content as a percentage (wt/wt) and phospholipid contents in milligrams per $100 \mathrm{~g}$ and Table 2 displays the phospholipid profile (i.e., the relative phospholipid contents as percentages of total phospholipid). Herein, we discuss the characteristics of the starting buttermilk and the effects of each subsequent processing stage.

\section{Buttermilk}

At $154 \mathrm{mg} / 100 \mathrm{~g}$, the average total phospholipid content of buttermilk was some 5 times greater than that of milk produced in the same geographical area (Ferreiro et al., 2015), a ratio intermediate between the ratios of 4 and 7 reported by Christie et al. (1987) and Elling et al. (1996), respectively. Given this ratio, and because the average fat content of buttermilk was $0.73 \%$ (wt/wt) whereas that of milk of the same area is about 3.8\% (Ferreiro et al., 2015), the ratio between the phospholipid contents of buttermilk fat and milk fat is around 27 (actual range 26-29 in our study). As mentioned, the greater phospholipid content of butter- milk is caused by the fragmented membranes of milk fat globules disrupted during the churning of cream mostly migrating to the aqueous phase (Corredig et al., 2003; Vanderghem et al., 2010), whereas the fat contents mostly aggregate as butter. In the current study, some $21 \%$ of the fat content of buttermilk was phospholipid.

The phospholipid profile of milk of this region is described by the descending order $\mathrm{PE}(\approx 39 \%)>\mathrm{PC}$ $(\approx 25 \%)>\mathrm{SM}(\approx 21 \%)>\mathrm{PS}(\approx 10 \%)>\mathrm{PI}(\approx 6 \%)$ (Ferreiro et al., 2015). In the present study, the phospholipid profile of buttermilk was similar except for the lower proportion of SM (mean 16.8\%), a difference that seems likely to be due to SM-rich membrane fragments binding more tightly to fat droplets than SM-poor fragments. This putative difference between the binding characteristics of SM-rich and SM-poor fragments was suggested by Britten et al. (2008) to explain their finding that butter serum had higher SM and lower PE contents than the corresponding buttermilk.

The average total phospholipid content of buttermilk in this study was 70 to $80 \%$ higher than those reported by Christie et al. (1987) and Rombaut et al. (2007; 90 and $84.7 \mathrm{mg} / 100 \mathrm{~g}$, respectively), but similar to that reported by Britten et al. (2008; $130 \mathrm{mg} / 100 \mathrm{~g}$ ). However, as a percentage of buttermilk fat, the $21.1 \%$ phospholipid content found in the present study is close to the $20.1 \%$ of Rombaut et al. (2007) and considerably higher than the $13.3 \%$ of Britten et al. (2008). This difference between the comparison of whole buttermilk

Table 2. Relative masses of individual phospholipids (\% of total phospholipid content) in the raw material and intermediate and final products in the production of buttermilk quark, and of the rinsings from washing ultrafiltration equipment (values are means of 5 production runs)

\begin{tabular}{llllll}
\hline Product & PE & PI & PC & PS & SM \\
\hline Buttermilk & 40.0 & 7.2 & 25.7 & 10.3 & 16.8 \\
Concentrated buttermilk & 37.9 & 7.2 & 25.5 & 10.1 & 19.4 \\
Cream-enriched concentrated buttermilk & 36.8 & 8.2 & 26.4 & 10.8 & 17.8 \\
Pasteurized cream-enriched concentrated buttermilk & 36.8 & 8.3 & 27.5 & 10.4 & 17.0 \\
Coagulate & 38.5 & 7.5 & 25.5 & 10.3 & 18.3 \\
Quark & 35.4 & 6.6 & 28.3 & 10.0 & 19.7 \\
Rinsings & 37.3 & 6.8 & 27.0 & 10.0 & 18.9 \\
\hline
\end{tabular}


and buttermilk fat contents highlights the importance of reporting fat content.

The PE, PI, PC, PS, and SM contents of total buttermilk phospholipid reported by Britten et al. (2008) were $39.0,8.9,24.4,8.3$, and $19.3 \%$, and those reported by Rombaut et al. (2007) 46.5, 9.6, 20.7, 9.3, and $13.9 \%$, respectively. In the present study, buttermilk phospholipid contained proportionately less SM than in that of Britten et al. (2008), proportionately less PE and PI than in that of Rombaut et al. (2007), and proportionately more PC, PS, and SM than was reported by Rombaut et al. (2007).

\section{Concentration of Buttermilk}

The concentration of buttermilk to half volume by UF almost doubled its fat content (Table 1) because milk fat does not pass through $50-\mathrm{kDa}$ membranes (although a proportion is retained on the membrane and lost during subsequent cleaning of the equipment). In particular, phospholipid was found in none of the ultrafiltrates analyzed in our study, whereas, in the microfiltration processes, transmembrane passage of $5.8 \%$ of phospholipids has been reported for membranes with $0.1-\mu \mathrm{m}$ pores (Morin et al., 2004) and $12.7 \%$ for $0.45-\mu \mathrm{m}$ membranes (Morin et al., 2006). That phospholipids were not passed in spite of being smaller than the $50 \mathrm{kDa}$ cut-off of the membranes is attributable to their being located in aggregates that were larger than $50 \mathrm{kDa}$, namely fat globule membrane fragments, which may have formed associations with casein during churning (Morin et al., 2007), or with $\beta$-LG and other milk proteins during the prior pasteurization of the cream from which the buttermilk was obtained (Corredig and Dalgleish, 1998; Ye et al., 2004; Morin et al., 2007).

Although no phospholipid passed into the ultrafiltrate, the average phospholipid content of the concentrated buttermilk was only about $50 \%$ higher than that of the original buttermilk, compared to an approximate $88 \%$ increase for total fat content, showing that proportionately more phospholipid than nonphospholipid fat was retained on the filtration membranes. The difference between the phospholipid content of concentrated buttermilk and its theoretical value (twice that of the unconcentrated buttermilk) was statistically significant $(P<0.05)$ for total phospholipid and all individual phospholipids except PS, for which a trend was noted $(0.05<P<0.10)$ due to its larger coefficients of variation. In terms of average recovery, that of total fat was $93.8 \%$, that of total phospholipid $75.4 \%$, and those of PE, PI, PC, PS, and SM were 71.9, 74.8, 74.7, 71.5, and $87.4 \%$, respectively. Except for SM, the recovery of a given phospholipid obtained in a single production run tended to be smaller the greater its concentration in the unconcentrated buttermilk.

That SM recovery was greater than that of other phospholipids is in keeping with the stronger association of SM-rich membrane fragments with fat droplets. We also noted that although almost all fat retained on membranes was washed out in the rinsings, showing it to have been retained in the so-called polarization layer, a significant amount of retained phospholipid failed to appear in the rinsings, meaning it was retained in the membrane pores (from which it had to be removed by chemical agents during final cleaning of the equipment).

\section{Enrichment of Concentrated Buttermilk with Cream and Homogenization and Pasteurization}

The addition of cream to the concentrated buttermilk raised its total fat content to about $5 \%$ (an increase by a factor of around 3.7), but because of the large difference between the phospholipid contents of buttermilk fat and milk fat this hardly affected its phospholipid content. The processes of homogenization and pasteurization reduced phospholipid contents fairly uniformly, with average recoveries of $91.4 \%$ for total phospholipid [somewhat lower than the $93 \%$ recovery reported by Morin et al. (2007) for pasteurization for $20 \mathrm{~s}$ at $85^{\circ} \mathrm{C}$ ], $92.0 \%$ for PE, $91.5 \%$ for PI, $94.9 \%$ for PC, $88.0 \%$ for PS, and $87 \%$ for SM. The difference in phospholipid content between the cream-enriched buttermilk before and after homogenization and pasteurization was statistically significant at the $P<0.05$ level for PI, PC, and total phospholipids, and at the $P<0.10$ level for PE, PS, and SM. These losses will have occurred through the joint action of homogenization, which by increasing the surface-to-volume ratio of fat globules favors the adsorption of casein on the membrane and the interaction of serum proteins with membrane proteins (Lee and Sherbon, 2002), and pasteurization (heat treatment), which favors the formation of covalent bonds between membrane fragments and proteins that become denatured and insoluble (Corredig and Dalgleish, 1998), with resultant deposition of these phospholipid-bearing protein-membrane associations on the walls of the pasteurization equipment.

\section{Coagulation}

During the coagulation of the pasteurized buttermilk by incubation with lactic acid bacteria, phospholipid contents rose by an average of $26.4 \%$ for PE, $12.5 \%$ for PI, $13.7 \%$ for PC, $15.1 \%$ for PS, $31.6 \%$ for SM, and $21.5 \%$ for total phospholipids. The difference between the phospholipid contents of the pasteurized buttermilk and coagulate was statistically significant at the $P<$ 
0.05 level for PC, PS, SM, and total phospholipid content, and at the $P<0.10$ level for PE and PI. The rise in phospholipid content is attributable to the synthesis phospholipids for cellular and intracellular membranes by the proliferating lactic acid bacteria.

\section{Separation of Quark and Permeate}

Concentration of the coagulate to half volume caused only a $2.3 \%$ loss of total fat but, as with the initial concentration of the starting buttermilk, much greater losses of phospholipids, with average recoveries of $67.6 \%$ for $\mathrm{PE}, 64.0 \%$ for PI, $81.7 \%$ for PC, $69.4 \%$ for PS, $77.2 \%$ for SM, and $72.9 \%$ for total phospholipid. For all phospholipids, the loss was statistically significant $(P<$ 0.05 ) and, except in the case of PC, somewhat greater than during the concentration of buttermilk. This difference between the effects of the 2 UF processes may be attributed partly to the greater DM content of coagulate, which must result in greater retention on filter membranes, and partly to the continuing influence of the association of protein and fat globule membrane induced by homogenization and pasteurization.

Due to the $2.3 \%$ loss of fat during separation of quark and whey, the average ratio between the total phospholipid contents of quark fat and coagulate fat was a little larger than the recovery reported above, 74.5 compared with $72.9 \%$, with similar rises for $\mathrm{PE}$ (69.0\%), PI (64.9\%), PC (83.1\%), PS (71.4\%), and SM $(78.7 \%)$.

The phospholipid content of the quark, $374 \mathrm{mg} / 100 \mathrm{~g}$, is 7.1-fold greater than the $52.6 \mathrm{mg} / 100 \mathrm{~g}$ reported by Rombaut et al. (2007). This difference is attributable not only to the larger fat content of our quark (10.32 vs. $6.83 \%$ ), but also, and in greater measure, to the difference in starting material, buttermilk instead of milk. Indeed, the phospholipid content of our quark fat, $3.62 \%$, is still 4.5 -fold larger than the $0.81 \%$ reported by Rombaut et al. (2007). Nevertheless, the phospholipid profile maintained, with little variation, throughout quark production in the present study $(\mathrm{PE}>\mathrm{PC}>$ SM > PS > PI) was very similar to that observed by Rombaut et al. (2007).

\section{CONCLUSIONS}

In this study the phospholipid content of buttermilk was around 5 times that of milk, and that of buttermilk fat around 27 times that of milk fat. The relative SM content of buttermilk was somewhat less than that of milk. During UF of buttermilk or coagulated buttermilk, phospholipids were not lost in permeate, but losses did occur due to retention on or in filter membranes. Phospholipids were also lost, though to a smaller extent, during homogenization and pasteurization; but during fermentation of concentrated buttermilk, phospholipid content increased-PE and SM contents especially - due to the formation of biological membranes by the proliferating bacteria. The relative abundances of individual phospholipids varied little during the production of buttermilk quark.

\section{ACKNOWLEDGMENTS}

We thank INNOLACT S.L. (Castro de Rey, Lugo, Spain) for its collaboration in this study.

\section{REFERENCES}

Britten, M., S. Lamothe, and G. Robitaille. 2008. Effect of cream treatment on phospholipids and protein recovery in butter-making process. Int. J. Food Sci. Technol. 43:651-657.

Christie, W. W., R. C. Nobel, and G. Davies. 1987. Phospholipids in milk and dairy products. Int. J. Dairy Technol. 40:10-12.

Contarini, G., and M. Povolo. 2013. Review. Phospholipids in milk fat: Biological and technological significance, and analytical strategies. Int. J. Mol. Sci. 14:2808-2831.

Corredig, M., and D. G. Dalgleish. 1998. Effect of heating of cream on the properties of milk fat globule membrane isolates. J. Agric. Food Chem. 46:2533-2540.

Corredig, M., R. R. Roesch, and D. G. Dalgleish. 2003. Production of a novel ingredient from buttermilk. J. Dairy Sci. 86:2744-2750.

Dewettinck, K., R. Rombaut, N. Thienpont, T. T. Le, K. Messens, and J. Van Camp. 2008. Nutritional and technological aspects of milk fat globule membrane materials. Int. Dairy J. 18:436-457.

Duivenvoorden, I., P. J. Voshol, P. C. Rensen, W. van Duyvenvoorde, J. A. Romijn, J. J. Emeis, L. M. Havekes, and W. F. Nieuwenhuizen. 2006. Dietary sphingolipids lower plasma cholesterol and triacylglycerol and prevent liver steatosis in $\mathrm{APOE}^{*} 3 \mathrm{Leiden}$ mice. Am. J. Clin. Nutr. 84:312-321.

Elling, J. L., S. E. Duncan, T. W. Keenan, W. N. Eigel, and J. Boling. 1996. Composition and microscopy of reformulated creams from reduced-cholesterol butteroil. J. Food Sci. 61:48-53.

FAOSTAT. 2015. World Cow Butter Production. Accessed Mar. 20, 2015. http://faostat3.fao.org/download/Q/QP/E.

Ferreiro, T., L. Gayoso, and J. L. Rodríguez-Otero. 2015. Milk phospholipids: Organic milk and milk rich in conjugated linoleic acid compared to conventional milk. J. Dairy Sci. 98:9-14.

FIL-IDF. 1996. International Standard 1D. Determination of fat content-Gravimetric method (Rösse-Gottlieb reference method). International Dairy Federation. Brussels, Belgium.

FIL-IDF. 2000. International Standard 141C. Whole milk. Determination of milkfat, protein and lactose content. Guidance on the operation of mid-infrared instruments. International Dairy Federation. Brussels, Belgium.

FIL-IDF. 2008. International Standard 222. Cheese. Determination of fat content. Van Gulik method. International Dairy Federation. Brussels, Belgium.

Govindasamy-Lucey, S., T. Lin, J. J. Jaeggi, C. J. Martirelli, M. E. Johnson, and J. A. Lucey. 2007. Effect of type of concentrated sweet cream buttermilk on the manufacture, yield and functionality of pizza cheese. J. Dairy Sci. 90:2675-2688.

Kuchta, A. M., P. M. Kelly, C. Stanton, and R. A. Devery. 1996. Milk fat globule membrane-A source of polar lipids for colon health? A review. Int. J. Dairy Technol. 65:315-333.

Lee, S. J., and J. W. Sherbon. 2002. Chemical changes in bovine milk fat globule membrane caused by heat treatment and homogenization of whole milk. J. Dairy Res. 69:555-567.

Mistry, V. V., L. E. Metzger, and J. L. Maubois. 1996. Use of ultrafiltered sweet buttermilk in the manufacture of reduced fat cheddar cheese. J. Dairy Sci. 79:1137-1145. 
Morin, P., R. Jiménez-Flores, and Y. Pouliot. 2004. Effect of temperature and pore size on the fractionation of fresh and reconstituted buttermilk by microfiltration. J. Dairy Sci. 87:267-273.

Morin, P., R. Jiménez-Flores, and Y. Pouliot. 2007. Effect of processing on the composition and microstructure of buttermilk and its milk fat globules membranes. Int. Dairy J. 17:1179-1187.

Morin, P., Y. Pouliot, and R. Jiménez-Flores. 2006. A comparative study of the fractionation of regular buttermilk and whey buttermilk by microfiltration. J. Food Eng. 77:521-528.

Rombaut, R., K. Dewettinck, and J. Van Camp. 2007. Phospho- and sphingolipid content of selected dairy products as determined by HPLC coupled to an evaporative light scattering detector (HPLCELSD). J. Food Compos. Anal. 20:308-312.

Rombaut, R., J. Van Camp, and K. Dewettinc. 2005. Analysis of phospho- and sphingolipids in dairy products by a new HPLC method. J. Dairy Sci. 88:482-488.
Sodini, I., P. Morin, A. Olabi, and R. Jiménez-Flores. 2006. Composition and functional properties of buttermilk: A comparison between sweet, sour, and whey buttermilk. J. Dairy Sci. 89:525-536.

Spitsberg, V. L. 2005. Invited review: Bovine milk fat globule membrane as a potential nutraceutical. J. Dairy Sci. 88:2289-2294.

Vanderghem, C., P. Bodson, S. Danthine, M. Paquot, C. Deroanne, and C. Blecker. 2010. Milk fat globule membrane and buttermilks: From composition to valorization. Biotechnol. Agron. Soc. Environ. 14:485-500.

Vesper, H., E. Schmelz, M. N. Nikolova-Karakashian, D. L. Dillehay, D. V. Lynch, and A. H. Merril. 1999. Sphingolipids in food and the emerging importance of sphingolipids to nutrition. J. Nutr. 129:1239-1250.

Ye, A., S. Harjinder, D. J. Oldfield, and S. Anema. 2004. Kinetics of heat-induced association of $\beta$-lactoglobulin and $\alpha$-lactalbumin with milk fat globule membrane in whole milk. Int. Dairy J. 14:389-398. 